\title{
Kultivasi Budaya Pemuda Kubu dalam Hutan-hutan Dharmasraya Sumatera Barat
}

\author{
Ahmad Arrozy*, Nenan Angenani Titis, Fuji Riang Prastowo \\ Golong Gilig Institute of Nusantara and Diaspora Studies Universitas \\ Gadjah Mada \\ Jl. Bulaksumur, Kabupaten Sleman, Daerah Istimewa Yogyakarta 55281
}

Submitted: 11 th Nov $2019 \quad$ Revised: 19th Nov 2019

Accepted: $10^{\text {th }}$ Jan 2020

Abstract This cultural study is based on the rights of the Kubu indigenous youth community in reacting to the mechanism of the oil palm plantation industry in the Dharmasraya Forests, West Sumatra Province. The expansion of the oil palm company in the Bulangan Forest caused the Kubu Community to move to the Padang Hilalang Forest and begin to pioneer the culture of cultivate. This cultural study uses observational data and grounded theory methods based on the Kubu cultural anthropological conceptualization that was initiated by Gerard Persoon (1989). The findings of this study are that the culture of shifting indigenous communities or the Melangun tradition has begun to disappear because forest space has increasingly been marginalized due to the presence of the oil palm industry mechanism. The results of the study show that the change in space in the form of forest which is the native habitatof the Kubu Community makes it a communal compulsion that it is necessary to continue living in the fields. The roles of public institutions such as government through the Department Social Service, Religion Institution and Universities in the fields of socio-cultural sciences to assist the Kubu community who have been deprived of their living space from the forests of West Sumatra, as well as efforts to document and reinforce native beliefs that are increasingly disappear.

Keywords: Change, culture, forest, living space

Abstrak Kajian budaya ini didasarkan kepada hak-hak komunitas pemuda adat Kubu dalam melakukan reaksi terhadap mekanisme industri perkebunan sawit di Hutan-hutan Dharmasraya, Provinsi Sumatera Barat. Ekspansi perusahaan sawit terhadap Hutan Bulangan menimbulkan Komunitas Kubu berpindah ke Hutan Padang Hilalang dan mulai merintis budaya berladang (the culture of cultivate). Kajian budaya ini menggunakan data-data observasi dan metode grounded theory berbasis konseptualisasi antropologi budaya Kubu yang dirintis oleh Gerard Persoon (1989). Temuan dari kajian ini adalah budaya komunitas adat yang berpindah atau tradisi 
Melangun mulai sirna karena ruang hutan semakin terpinggirkan karena keberadaan mekanisme industri sawit. Hasil kajian menunjukkan perubahan ruang berupa hutan yang merupakan habitat asli (native habitus) dari Komunitas Kubu membuat keterpaksaan secara komunal bahwa perlu melanjutkan hidup secara berladang. Fungsi institusi publik seperti pemerintahan melalui Dinas Sosial, Kanwil Agama RI dan Universitas bidangbidang ilmu sosial-budaya untuk melakukan pendampingan komunitas Kubu yang tercerabut ruang hidupnya dari hutan-hutan Sumatera Barat, sekaligus usaha untuk melakukan dokumentasi dan penghayatan kepercayaan leluhur (native believes) yang semakin sirna.

Kata Kunci: budaya, hutan, perubahan, ruang hidup

\section{PENDAHULUAN}

Manusia membangun peradaban dengan cara merancang ruang habitat yang dihuni, sehingga setiap perubahan menjadi pembentuk tradisi dan pemikiran manusia yang menempatinya. Dalam perbincangan mengenai penempatan ruang terdapat kategorisasi dan pemanfaatan ruang umumnya dipilah berdasarkan sifat dan jangka waktu yaitu nomaden dan permanen (Deleuze and Guattari 1987: 380). Pola tradisi kehidupan nomaden dari ruang satu ke ruang lain beserta dinamika berburu masih dipertahankan oleh sejumlah suku-suku minoritas di Indonesia. Meskipun masyarakat pasca tradisional di Indonesia telah menetapkan untuk menduduki sebuah ruang permanen (Jayadi, Demartoto, \& Kartono 2018). Salah satu suku yang belum sepenuhnya berakulturasi dengan masyarakat modern lainnya bisa ditemukan di Sumatera Selatan, komunitas ini dikenal dengan nama suku Kubu.

Komunitas Kubu hidup berpindah-pindah melintasi ragam corak geografi, dari rawa dekat laut, hutan hingga kaki bukit dan pegunungan (Syuroh 2011:180). Bagi masyarakat dengan pola pemenuhan kebutuhan bergantung pada hutan, konversi fungsi lahan dan meningkatnya permintaan pasar pertanahan yaitu ekspansi perkebunan sawit menjadi ancaman perubahan habitat. Pada dasarnya, konflik ekologi kerap ditandai dengan kekuasaan asimetris antara pihak yang mencemari lingkungan dengan pihak pada posisi mempertahankan habitatnya (Jeong 2001: 6).

Studi antropologi hukum yang dilakukan Jose Martinez Cobo (1986) dibawah lembaga United Nations (UN) menjadi dasar negara dan korporasi yang sedang berkembang untuk memperhatikan orientasi 
komunal yang berbeda dengan pola hidup masyarakat urban.Cobo mencoba menarik elemen subjektif dengan elemen objektif dari komunitas adat yang menjadi distingsi dari komunitas pada umumnya, dengan pokok berikut: a)hubungan yang khas dengan tanah atau wilayah secara pewarisan dan telah ditinggali atau digunakan, b)keberlanjutan sejarah, c)karakteristik kultural yang khas, d)nondominan, e)identifikasi diri dan kesadaran berkomunitas (Bosko, 2006: 59; Muazaroh, S., \& Subaidi, S. (2019). Bahkan Cobo (1986) menyatakan bahwa: "adalah penting untuk mengetahui dan mengerti hubungan yang sangat khusus dan bersifat spiritual antara komunitas adat dengan tanahnya, yang mendasar bagi eksistensi komunal untuk semua kepercayaan, tradisi, beserta budaya".

Bagi komunitas adat, tanah bukan lagi sekadar barang yang dimiliki atau alat produksi, akan tetapi keseluruhan hubungan antara kehidupan spiritual dengan ibu pertiwi atau tanah kelahiran mereka yang melekat bagi tubuh dan gerak komunal (Bosko, 2006; Huda, M. T., \& Khasanah, I. K. 2019). Tanah dalam makna komunitas adat bukan suatu komoditas yang dapat diperoleh tapi suatu elemen atau unsur yang dapat dinikmati secara komunal. Tanah-tanah dalam penetapan area hutan alami merupakan ruang hidup untuk menggantungkan hidup komunitasnya kepada apa yang telah disediakan oleh hutan dan lingkungannya. Komunitas adat memenuhi kebutuhan hidupnya yang mendasar (subsistence) dari alam sekitarnya. Komunitas adat yang terbiasa hidup di hutan, lazimnya mengumpulkan atau mengolah sebagian kecil apa yang ditemukan di hutan (Bosko, 2006; Li 2001). Secara komunal, telah menerapkan beragam praktik agro-kehutanan berbasis pengetahuan yang mendalam tentang lingkungan alami (Bosko, 2006).

Dinamika sosio-ekonomi modern terhadap lahan dan ruang hidup akhirnya mempengaruhi kualitas hidup masyarakat sekitar: orang Kubu dan orang Melayu di Jambi. Meskipun hidup dalam satu lingkungan yang sama, interpretasi salah satu komunitas terhadap rekayasa ruang bisa berbeda dengan komunitas masyarakat lainnya. Komunitas Melayu dan Transmigran-Jawa memiliki tendensi untuk lebih terbuka terhadap perubahan bentang alam di Jambi, dengan tindakan aktif dalam perubahan fungsi hutan, pembukaan lahan baru, dan pengelolaan sumber daya alam. Perubahan ruang hidup dan konversi fungsi lahan mempengaruhi keberadaan kelompok sukubangsa yang mendasarkan hidupnya pada hutan sehingga mengusir masyarakat suku Kubu secara perlahan dari habitatnya.

Minimnya kebijakan pemerintah dalam negosiasi antar suku bangsa tentang perubahan lingkungan, pengelolaan sumber daya alam yang 
terbatas tersebut, akhirnya terjalin hanya dalam interaksi ekonomi pasar (Prasetijo 2007 :11). Dalam kondisi interaksi ini, keterlibatan bujang (pemuda) dari suku Kubu memerankan peran penting. Yaitu interaksi di luar komunitas yang berhubungan dengan jual-beli dan tawar-menawar cenderung diwakilkan oleh bujang. Meskipun secara garis besar perjanjian dan keputusan perekonomian dalam komunitas Kubu dikelola oleh tetua adat (sesepuh adat). Dalam interaksi ekonomi tersebut, secara tidak langsung bujang dihadapkan kepada dua pengetahuan budaya yang berbeda tentang lingkungan.

\section{Keberadaan Komunitas Kubu di Hutan Bulangan, Sumatera Barat}

Secara ekologis, Komunitas Kubu dapat dikatakan hidup tersebar di tiga wilayah berbeda, yaitu di daerah bagian barat Provinsi Jambi (sekitar jalan lintas timur Sumatera), kawasan Taman Nasional Bukit Dua Belas (Taman Nasional Bukit Dua Belas), dan Orang Kubu yang tinggal di bagian utara Provinsi Jambi, terutama di Taman Nasional Bukit Tiga Puluh (berada di perbatasan antara Riau - Jambi) (Prasetijo 2007:16). Kajian ini berfokus pada Rombong Kubu di Hutan Bulangan dan Hutan Padang Hilalang yang merupakan bagian dari Komunitas Kubu yang mendiami area hutan-hutan dan perbukitan di Kabupaten Dharmasraya. Rombong Kubu di Hutan Bulangan dan Hutan Padang Hilalang masih belum tercatat dalam kajian antropologi Indonesia. Rombong Kubu memiliki pola hidup yang berbeda satu dengan yang lainnya meskipun berasal dari komunitas yang sama.

Dua pola kehidupan dalam Komunitas Kubu, yaitu Rombong Kubu yang hidup dalam pemukiman PKMT (Pemukiman Kembali Masyarakat Terasing) seperti yang ada di PKMT Lubuk Sepuh, Pulau Lintang dan Sungai Pingai; dan Rombong Kubu yang tetap hidup nomaden diantara kebun-kebun karet dan sawit milik Orang Melayu dan Orang Jawa dalam kebijakan transmigrasi. Komunitas tetap dapat hidup mengembara bersama keluarganya (mobilitas residensial) layaknya hidup berpindahpindah didalam hutan (Prasetijo 2015).

Pada dasarnya kebutuhan makanan pokok komunitas Kubu Hutan Bulangan dipenuhi dari sumber daya hutan. Makanan pokok Rombong Kubu biasanya terdiri atas ubi, ikan sungai dan daging babi hasil buruan. Di hutan Rombong Kubu mengolah buah-buahan, umbi, dan damar yang pada umumnya, tidak selalu dilakukan oleh kaum perempuan (Syuroh 2011).

Berbeda dengan Rombong Kubu di Jambi ataupun di Sumatera Selatan, rombong Kubu di Dharmasraya masih mengadopsi adat Minang, salah satunya sistem garis matrilineal atau garis ibu (Arsa 2019). Setiap 
Rombong Kubu di Jambi dikepalai oleh Pak Syirah yang merupakan jabatan ketua adat, sedangkan Rombong Kubu Dharmasraya dikepalai oleh Sesepuh Perempuan dan Pak Camat. Sesepuh perempuan berperan mengelola segala macam hasil panen dan buruan, sedangkan Pak Camat merupakan julukan perwakilan kaum pria Kubu untuk hubungan antar komunitas. Dahulu Pak Camat dipimpin oleh Amir yang merupakan kakak dari Bunga Marni, pemimpin Rombong Kubu di Hutan Bulangan.

Bagi komunitas Kubu, keberadaan hutan tidak hanya untuk memenuhi kebutuhan ekonomi tetapi hutan menjadi sumber pangan dan identitas. Konversi hutan berpengaruh besar pada identitas kelompok Kubu dan tradisinya yang telah berlangsung lama. Perubahan fungsi tersebut sifatnya masif dan mendasar, bahkan ketika kelompok masyarakat telah mendapatkan ganti dari kerugian yang mereka alami. Sebagaimana komunitas adat di Peru yang berhasil negosiasi dengan perusahaan tambang dan mendapatkan ganti rugi berupa pemukiman baru dengan fasilitas yang layak (Li 2000). Akan tetapi mereka masih mengalami kehilangan tradisi dan pekerjaan yang sesuai dengan nilai budaya mereka.

Catatan lapangan mengenai fakta mental (mentifact) yang terekam pada sesepuh Kubu Rombong Poniran adalah hutan sebagai lingkungan utama komunitas untuk mengolah dan melestarikan hutan yang dianggap bersemayam dewa-dewa dari berbagai bunga-bunga yang tumbuh maka dari itu bagi Poniran maupun Amir (Pak Camat Kubu yang telah meninggal, dan kakaknya Marni) hutan adalah milik Tuhan bukan manusia. Bagi Poniran dan Amir, Indonesia dianggap masih dipimpin oleh Sukarno, maka dari itu kedua ketua adat Kubu ini masih menganggap hutan mereka adalah hutan Sumatera Tengah yang terdiri dari Hutan Padang Hilalang (Banai), Hutan Bulangan, Hutan Batang Bakur, Hutan Tebing Tinggi, Hutan Sitiung (padahal sekarang Sitiung sudah jadi Pemukiman Jawa), bahkan sampai hutan-hutan di Jambi yaitu Merangin dan Bukit Dua Belas. Penetapan akan catatan mental berdasarkan kajian etno-historis yang dilakukan Denys Lombard (2018)dengan konsep batas-batas pembaratan (Lombard, 2018).

Perubahan budaya terjadi dalam setiap masyarakat, namun proses dan jangkauannya berbeda dengan yang lainnya. Dengan latar belakang tersebut, kajian ini bertujuan untuk menggambarkan perubahan budaya yang dialami oleh Komunitas Kubu. (i) Mengenal Komunitas Kubu di Dharmasraya; (ii) Memahami bentuk interaksi Komunitas Kubu Dharmasraya dengan lingkungannya; (iii) Melakukan identifikasi dampak perubahan interaksi tersebut terhadap kultivasi budaya pemuda Kubu di Dharmasraya; dan(iv) Menggambarkan keterlibatan dan peran 
pemuda Kubu dalam interaksi tersebut.Dalam rumusan kajian ini, peneliti berupaya mengungkapkan apa yang terjadi, jika hutan sebagai ruang regenerasi pendidikan lingkungan pemuda Kubu mulai sirna oleh keberadaan mekanisme industri sawit, kemudian mengapa terdapat peralihan ke peran pemuda Kubu.

\section{METODE PENELITIAN}

Penelitian ini menggunakan analisa kualitatif yang secara sistematis dapat menghasilkan konsep lapangan berbasis data observasi. Regular basis dalam penelitian dimulai dengan induktifikasi atau berdasarkan temuan realita lapangan (Neuman 2014). Metode ini dikenal dengan grounded theory yang dikembangkan Glaser dan Strauss dalam The Discovery of Grounded Theory (1964).Metode grounded theory memiliki komponen sebagai berikut: a. Pengumpulan data dan analisis secara simultan, b. Melacak tema yang timbul di akar rumput melalui analisa data awal, c. Pengambilan kriteria informan, d. Melakukan rincian penyebab, kondisi, dan konsekuensi dari proses yang dipelajari (Maykut and Morehouse 1994).Pakar sosiologi menggunakan metode ini didorong untuk menjaga analisis dalam batas-batas data yang ditemukan (Neuman 2014). Lalu menarik konsep abstrak berdasarkan pengamatan empiris. Operasional grounded theory berdasarkan hubungan penalaran yang ditemukan dalam konsep realita lapangan (Strauss and Corbin 1994: 278). Kajian budaya Kubu ini dilaksanakan di dua lokasi yaitu Nagari Banai Hutan Padang Hilalang pada tanggal 24 Mei hingga 29 Mei 2019, kemudian Nagari Bonjol yang memiliki Hutan Bulangan telah dilaksanakan pada tanggal 16 Juni hingga 4 Juli 2019. Kedua lokasi tersebut di Kecamatan IX Koto dan Kecamatan Koto Besar Kabupaten Dharmasraya Provinsi Sumatera Barat. Berikut peta Kabupaten Dharmasraya akan disajikan:

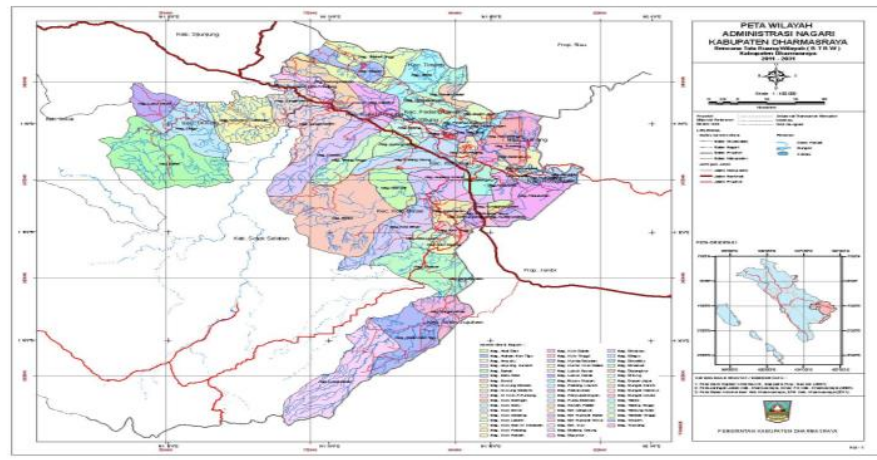

Sumber: Rencana Tata Ruang Bappeda

Kabupaten Dharmasraya, 2011-2031 


\section{Observasi}

Peneliti didampingi guide lokal yang berasal dari lembaga swadaya setempat bernama Perkumpulan Peduli dan Pundi untuk memberikan keterangan penelitian kepada Bappeda Dharmasraya dan Kesbangpol, kemudian bertemu dengan kepala camat Koto Besar dan kepala nagari Bonjol dan Banai. Pasca pemberian keterangan penelitian budaya kepada otoritas setempat, peneliti live in di pemukiman yang berdekatan dengan lokasi rombong Kubu yang masih berpindah-pindah dari hutan satu ke hutan lain, dari kebun satu ke kebun lain. Kelompok Kubu dalam sebutan setempat disebut sebagai Rombong, dari area Dharmasraya terdapat Rombong Marni dan Penyiram, sedangkan dari daerah Jambi terdapat Rombong Ucup dan Rombong Tahir.

Guide lokal menjadi instrumen kajian budaya ini, karena menerjemahkan bahasa Komunitas Kubu dan jajak pendapat Komunitas Minang, Melayu, dan Jawa mengenai interaksi dengan Komunitas Kubu. Guide lokal di area Banai bernama Yurnalis yang menjabat sebagai kepala dusun atau sebutan lokal disebut kepala jorong, sedangkan di area Bonjol bernama Roni Heriadi sebagai pegiat LSM dan berpindah ke Syafril yang menjabat sebagai petugas penyuluh sosial-budaya dari Kecamatan Koto Besar. Perihal rombong Marni di area hutan BonjolBulangan bermigrasi ke arah Kecamatan Silago mengikuti Rombong Poniran (atau sebutan luar "Penyiram") sehingga tidak sempat bertemu dengan Rombong Marni, hingga hanya mampu bertemu dengan tetangga kebun dari Rombong Marni yaitu seorang pekebun bernama Ahmat Daud yang berusia 63 tahun.

\section{Data Grounded}

Pengumpulan data dari metode grounded berdasarkan catatan lapangan (field notes) dan wawancara pelaku budaya yaitu salah satu anggota komunitas Kubu baik dari Rombong Poniran dan Rombong Marni melalui instrumen riset yaitu guide lokal yang mengerti bahasa dan adat istiadat (custom) Komunitas Kubu (Bryman and Burgess 1994). Informasi dari pelaku budaya diterjemahkan melalui guide lokal terlebih dahulu kemudian dicatat dan direkam melalui kertas kerja lapangan. Teknis perekaman menggunakan aplikasi voice.recorder milik Olympus dengan output data format MP3 Audio dan M4A dengan ukuran rata-rata 118.4 MB beserta durasi 2 jam 3 menit dan tertanggal 26 Mei-30 Juni 2019. Spesifikasi data audio dalam tabel berikut: 
Tabel 1. Daftar Data Audio

\begin{tabular}{|c|l|l|l|l|}
\hline No & \multicolumn{1}{|c|}{ Identitas Informan } & Waktu Rekaman & Jenis Files & \multicolumn{1}{|c|}{ Ukuran } \\
\hline 1 & Idar (Perempuan Kubu) & 26 Mei 2019. & MP3Audio & $38.8 \mathrm{MB}$ \\
\hline 2 & Poniran(Sesepuh Kubu) & 26 Mei 2019. & MP3Audio & $11.3 \mathrm{MB}$ \\
\hline 3 & Pendriyansyah Piliang & 27 Mei 2019. & MP3Audio & $48.4 \mathrm{MB}$ \\
\hline 4 & Ahmat Daud & 30 Juni 2019 & MP3Audio & $118.4 \mathrm{MB}$ \\
\hline
\end{tabular}

Data grounded dilakukan dengan eksplorasi persepsi yang merupakan aktivitas komunal dalam memberikan pengakuan, kesan, dan opini atas apa yang dialami pelaku budaya (Zoa, 2009). Persepsi merupakan ekspresi perilaku pelaku budaya dalam melakukan reaksi terhadap institusi, komunitas atau aktor (Zoa; Diaw; Aseh; Prabhu, 2009).

\section{Kerangka Konsep}

Kultivasi budaya Kubu merupakan konsep antropologi budaya dari Gerard Persoon yang melakukan kerja lapangan (fieldwork) pada tahun 1977-1978, 1979-1982, dan 1985 di Sumatera Selatan. Persoon menyebutkan bahwa Komunitas Kubu mulai beralih ke luar batas ruang hutan (to be interaction outside world) semenjak ada ilegal logging, kegiatan misionaris, dan tindakan institusi dari pemerintahan setempat. Kultivasi budaya merupakan tindakan penanaman budaya modern terhadap komunitas asli yang semasa itu wacananya dianggap 'komunitas primitif, karena terdapat sekuriti perkebunan yang dibimbing secara resmi oleh Dinas Kepolisian maka cara berburu Kubu mulai berubah dari senjata tradisional berupa tombak beralih ke senjata modifikasi yaitu senapan api. Hal ini dalam kacamata Gerard Persoon merupakan modifikasi berburu karena tekanan asimilasi dari dominasi masyarakat yang menunjukkan variasi dari berbagai reaksi komunitas Kubu yang menyimpulkan interaksi bagi Kubu terhadap masyarakat di luar Kubu (Persoon 1989: 507). Dalam kacamata Gerard Persoon (1989) terdapat framing grounded berdasarkan kajian antropologi budaya dengan konsepsi sebagai berikut:

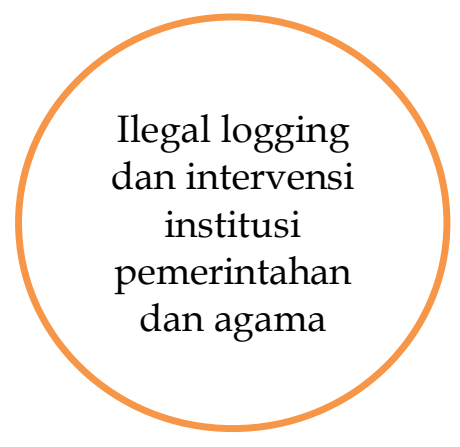

42 |

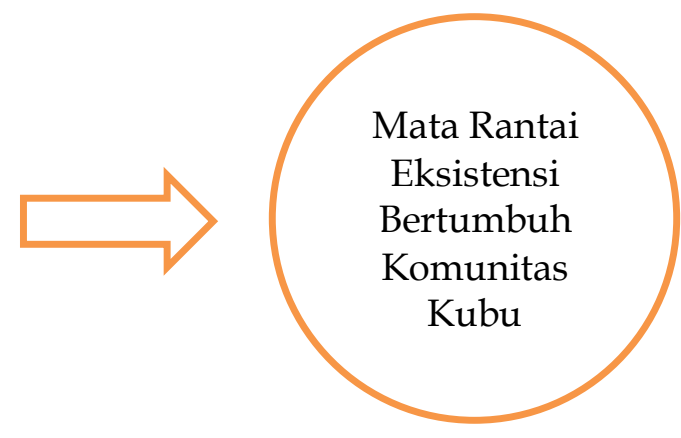

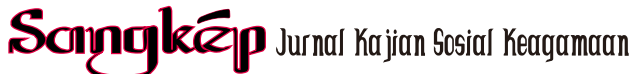




\section{HASIL DAN PEMBAHASAN}

Eksistensi komunal Kubu terbentur dengan struktur komunitas Minang yang mapan dengan menganggap Suku suatu area teritori atau Desa (Nagari) di mana klaim kepemilikan lahan menjadi kendala(obstacle) bagi tercapainya penerimaan masyarakat. Dalam catatan lembaga swadaya setempat terdapat dua unit Rombong komunitas Kubu yaitu Penyiram (menurut julukan orang luar) dan Marni yang jaraknya $40 \mathrm{~km}$ dalam area kehutanan yaitu dari Hutan Padang Hilalang (Desa Banai, Kecamatan IX Koto) menuju Hutan Bulangan (Desa Bonjol, Kecamatan Koto Besar). Hutan merupakan ruang habitat asli (native habitus) bagi Rombong Kubu. Kepercayaan leluhur Suku Kubu bahwa semua bunga adalah dewa yang diberikan nyawa oleh matahari. Hutan Padang Hilalang, hutan Batang Bakur, dan hutan Bulangan. Bagi Kubu kepemilikan adalah "hutan adalah milik Tuhan ". Hal ini menjadi konsep kepemilikan bagi Komunitas Kubu (Li 2001).

Rombong Poniran di Hutan Padang Hilalang masih tergolong lebat sehingga suplai vegetasinya tidak terganggu untuk pengobatan lokal. Adanya ekosistem hutan lebat yang menyuplai komunitas Kubu, sebaliknya di Rombong Marni, dimana ekosistem hutan lebatnya sudah habis karena tergusur oleh perusahaan perkebunan sawit malah dianggap eksklusif karena terbangunnya pemukiman karyawan bagi perusahaan sawit. Tiga perusahaan sawit yang mendiami hutan Bulangan itu terdiri dari perseroan terbatas AWB, SMP, dan Incasi Raya (Fieldnote, 18-Juni-2019).

Batas perkebunan milik pabrik AWB dengan kebun sawit milik perseorangan dibatasi oleh Pos Satpam (atau Sekuriti Perkebunan yang dibimbing secara resmi oleh satuan kepolisian Brimob). Menurut informasi guide lokal Roni Heriadi bahwasanya dibutuhkan 1000 hektar rehabilitasi bagi habitat asli rombong Kubu dengan status hutan lindung sebagaimana perbandingan bukit Dua Belas dan Hutan Merangin.

Tempat tinggal Rombong Marni di hutan Bulangan hanya berukuran $6 \mathrm{~m} \times 6 \mathrm{~m}=36 \mathrm{~m} 2$ (Fieldnote, 18-Juni-2019). Dindingnya masih kayu dan bambu beserta lubang-lubang angin yang ditutupi terpal berwarna biru. Plafon dari atap rumah rombong Marni juga ditutupi oleh terpal berwarna biru. Halaman dan kebun pondok Marni dengan luasan tanah 60 meterpersegi hingga 72 meter persegi. Peneliti sempat memegang tanah dari halaman pondok Marni dan terasa panas karena campuran material lumpur, pasir, dan limbah buangan akar-akar sawit yang menjalar (Fieldnote, 18-Juni-2019).

Pergeseran hukum untuk status Hutan Bulangan merupakan produk dualisme hukum antara hukum adat Minang dengan hukum negara yang 
sebetulnya sejak PT Tidar Kerinci Agung (TKA) mulai diimplementasikan pada tahun 1987. Lalu mereka menginjak di Bulangan dan Tebing Tinggi melalui anak perusahaan PT. Incasi Raya dan PT. AWB. Area hutan Bulangan memiliki tiga lapis hukum yaitu Hukum Adat Minang, Hukum Negara, dan Hukum Adat Kubu. Dalam sejarahnya, TKA diberikan Hak Guna Usaha (HGU) yaitu antara kepemimpinan Gubernur Azwar Anas (Gubernur Sumatera Barat tahun 1987) dan Bupati Darussapaan (Semasa itu Bupati Sijunjung). Bulangan sesungguhnya adalah julukan sungai setempat namun lambat laun menjadi nama hutan dalam sejarah lisannya (Fielnote, 19-Juni-2019).

Dengan adanya perusahaan grup sawit tersebut, menambah pabrikpabrik pengolahan komoditi kelapa sawit berupa CPO (Crude Palm Oil), pengolahan dari bahan mentah kelapa sawit ke CPO dalam skala besar menghasilkan udara panas bagi lingkungan Bulangan dan Desa Bonjol. CPO adalah minyak kelapa sawit mentah yang berwarna kemerahan yang diperoleh dari hasil estraksi atau proses pengempaan daging buah kelapa sawit. Pasca diolah maka dikirim melalui truk-truk tangki Fuso untuk pelbagai industri seperti sabun yang dikirim ke Unilever, industri baja sebagai pelumas, industri oleokimia (fatty acids, fatty alcohol, glycerin, dan biodiesel), dan terakhir industri makanan seperti minyak goreng dan margarin (Elvawati; Dharmawan; Damanhuri; Sumarti 2019). Ahmat Daud menuturkan Rombong Marni hanya dimanfaatkan sebagai partisan penjaga hutan tanaman industri. Mekanisme industri sawit tanpa dialog antar komunitas adat menimbulkan konflik kepemilikan lahan karena perbedaan mendasar konsep kepemilikan antara adat Kubu dengan adat kelompok mayoritas dan aturan UU Negara. Perubahan ruang habitat hutan membuat Rombong Marni bernegosiasi dengan aparat perkebunan dan Brimob. Dan hal itu memperluas marjinalisasi bagi Rombong Marni. Dari sekian catatan ini menimbulkan catatan realita dalam grounded framing mengenai ekosistem atau mata rantai yang menimbulkan keterpinggiran bagi kelompok Kubu (Rombong Marni) dari hutan Bulangan dan wilayah desa Bonjol. Frame grounded Ruang Hutan Bulangan sebagai berikut:

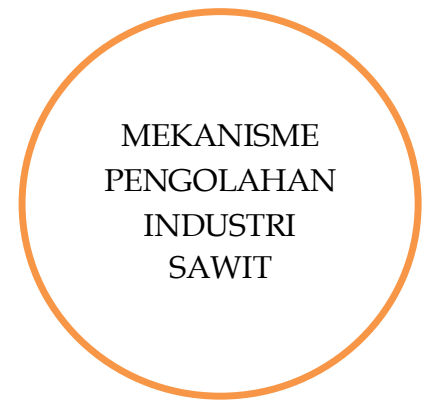

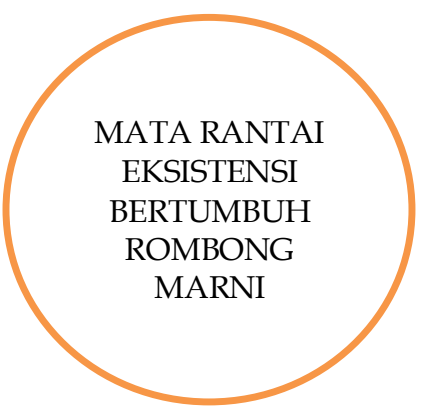

Sonng kēp Jurnal Kajian Sosial Keagamaan 
Framing ruang hutan Bulangan memberikan petunjuk bahwa mekanisme industri sawit menyebabkan mata rantai eksistensi bertumbuh anak-anak Rombong Marni terganggu karena sirkulasi industri sawit sehingga Rombong Marni memilih berpindah ke Pasar Kecamatan Silago.

\section{Tabel. 2: Temuan Dalam Kerangka Grounded}

\begin{tabular}{|l|l|l|l|}
\hline Rombong & \multicolumn{1}{|c|}{ Penyebab } & \multicolumn{1}{c|}{ Kondisi } & \multicolumn{1}{c|}{ Konsekuensi } \\
\hline $\begin{array}{l}\text { Rombong } \\
\text { Poniran }\end{array}$ & $\begin{array}{l}\text { Karena } \\
\text { dianggap sering } \\
\text { meminta-minta } \\
\text { kepada orang } \\
\text { kampung. }\end{array}$ & $\begin{array}{l}\text { Hutan Padang } \\
\text { Hilalang masih } \\
\text { lebat. }\end{array}$ & $\begin{array}{l}\text { Berladang durian dan } \\
\text { buah kabau. Dan ini ini } \\
\text { menanam dan memanen } \\
\text { adalah kelompok } \\
\text { pemuda Kubu. }\end{array}$ \\
\hline $\begin{array}{l}\text { Rombong } \\
\text { Marni }\end{array}$ & $\begin{array}{l}\text { Semakin } \\
\text { sedikitnya } \\
\text { pasokan } \\
\text { vegetasi dan } \\
\text { binatang } \\
\text { buruan di } \\
\text { Hutan } \\
\text { Bulangan. }\end{array}$ & $\begin{array}{l}\text { Tanah di Hutan } \\
\text { Bulangan terasa } \\
\text { panas dan air } \\
\text { sungai keruh } \\
\text { akibat } \\
\text { perkebunan } \\
\text { sawit. }\end{array}$ & $\begin{array}{l}\text { Bermigrasi ke arah } \\
\text { Hutan Padang Hilalang } \\
\text { dan bergabung dengan } \\
\text { Rombong Poniran. }\end{array}$ \\
\hline \multicolumn{2}{|l|}{ Sumber Marvang } \\
\hline
\end{tabular}

Sumber: Marvasti, 2004; Neuman, 2014; Zoa, 2009

Tabel temuan tersebut menunjukkan bahwa Rombong Marni terpaksa melakukan budaya ladang berpindah (shifting cultivation) walaupun memerlukan dukungan dari Rombong Poniran dan Idar sebagai sesepuh adat bagian perempuan. Motif migrasi Rombong Marni karena ruang hutan Bulangan telah didominasi oleh hutan tanaman industri sawit yang dikuasai mega korporasi sawit dengan kebun-kebun sawit milik perseorangan (Prastowo; Faridl; Arrozy; Anggraini 2019).

Interaksi antara komunitas adat mayor (Minang, Melayu, dan Jawa) dengan komunitas adat Kubu sebagai minoritas adalah masih hubungan jual-beli antara pertukaran kabau, jenang, rotan, labi-labi, duren, singkong, cabe dan babi hutan dengan kendaraan pengangkut bersama seperti pick-up dan motor. Meskipun Marni pernah berusaha berjualan cabe di pasar sungai rumbai namun tidak laku karena orang takut dan dianggap kumuh terhadapnya maka jualannya ia titipkan kepada tetangganya (orang kampung) yang sudah ia percayai (walaupun Marni rugi karena hasil panennya untuk biaya penjualan yang ia serahkan kepada orang kampung), lalu ia bermigrasi ke Silago untuk tetap 
berjualan yang sudah ia panen di hutan dan ladang miliknya (Prastowo; Faridl; Arrozy; Anggraini 2019).

Intensitas komunitasnya dalam berjualan maupun sering didatangi orang Dinas maupun pejabat pemerintahan setempat maka orang Kubu makin meninggalkan busana aslinya seperti celana kulit bagi pria dan kemben bagi perempuan karena merasa malu (ashamed) yang selanjutnya hutan semakin tidak nyaman ditinggali dengan busana seperti itu, karena hutannya sudah mulai sawit atau karet. Dalam kajian ini ada beberapa metafora berdasarkan temuan lapangan tentang perubahan budaya yang mengarah kepada kultivasi budaya pemuda Kubu:

a. Dari Tombak ke Gobok: Perubahan alat senjata berburu bagi Komunitas Kubu dari tombak ke senapan api rakitan (gobok) sejak 2001, hal ini dikarenakan banyaknya interaksi dengan komunitas hobi pengguna senjata api yang digunakan untuk berburu (Perbakin) yang notabene orang kaya baru beserta dengan oknum Brimob.

b. "Bodo Amat Soal Babi Yang Penting Dapat Garam ": Garam yang dimaksudkan disini adalah istilah temuan lokal yang berarti uang dimana sebetulnya Kubu sekarang sudah mulai memasak dengan garam. Sempitnya hutan yang telah dialihfungsikan menjadi perkebunan sawit merupakan kondisi yang mengharuskan Kubu menjual babi atau mengolahnya sehingga dapat diracik dengan garam.

c. "Ah Terpaksa Berladang, Pengalaman Daud ". Berladang merupakan inisiatif Idar dan Marni karena hasil berburu hanya cukup bagi kaum pria Kubu selain karena vegetasi hutan mulai menipis (atau hutan semakin homogen). Berladang merupakan salah satu tindakan komunal bagi Kubu tentang pemanfaatan tanah dari stimulasi hibah tanah dengan menarik garis batas kepemilikan dari ladang-ladang milik masyarakat mayor sehingga menjadi tahapan keterpaksaan yaitu semi-menetap (shifting cultivation).

Berikutnya juga dengan pemanfaatan pembelian pick-up dan motor karena kegunaannya untuk mengangkut hasil panen ke pasar yang bisa dijualnya. Adapun gaya hidup yang rambutnya direbonding, memakai kalung dan gelang, memakai arloji tembaga, merokok, minum coca-cola, dan masak mie instan merupakan eksistensi yang tumbuh secara pilihan personal saja dan ekspresi menikmati hasil panen.

Budaya "berladang" sangat berbeda dengan budaya berkebun atau berburu. Berladang merupakan bentuk ekosistem dan tahap berkemajuan dalam evolusi dari budaya berburu (Geertz 1983:13-15). Antropolog Geertz menggarisbawahi dari temuan Gourou (1956) bahwa tipikal berladang dijalankan pada ruang kawasan yang masih tropis (Geertz 1983: 15). 
Budaya berladang (swidden agriculture) ini mulai dilakukan kelompok pemuda Kubu yang merintis perladangan mulai dari menanam, mengairi, memupuk, dan memanen. Lazimnya ini dilakukan anak dari Idar yaitu Bujang Kocik, Dewi, dan Yusup, walaupun kelompok pria Kubu masih diwajibkan berburu, karena berburu masih dianggap pertanda kedewasaan pria Kubu. Maka rata-rata yang merawat ladangladang Kubu adalah perempuan muda dari Kubu seperti Dewi dan Lena. Hasil panen dari berladang tetap diserahkan kepada sesepuh perempuan Kubu seperti Idar dan Marni karena memang masih garis matrilineal sebagaimana pengaruh budaya Minang. Dewi, Lena, Bujang, dan Ucup merupakan hasil regenerasi dari perubahan ruang yang diaktifkan oleh sesepuh perempuan Idar dan Marni.

\section{KESIMPULAN}

Perubahan ruang berupa hutan yang merupakan habitat asli dari Komunitas Kubu membuat keterpaksaan secara komunal bahwa perlu melanjutkan hidup secara berladang. Budaya berladang ini tidak ada dalam tradisi sesepuh Kubu namun karena perubahan ruang tersebut, akhirnya budaya berladang (swidden agriculture) dirintis oleh pemuda dan pemudi Kubu demi melanjutkan sesuap pangan bagi sesepuh Kubu maupun cucu-cucu dari Rombong Poniran yang ada di hutan Padang Hilalang dan desa Banai, sedangkan Rombong Marni memutuskan untuk bermigrasi ke hutan-hutan yang dekat dengan pasar kecamatan Silago. Langkah Rombong Marni masih dalam tahapan berladang berpindah (shifting cultivation).

Perubahan ruang habitat komunitas Kubu merupakan dampak alihfungsi hutan Bulangan menjadi komplek hutan perkebunan sawit baik milik perseorangan maupun perusahaan grup sawit yang menggerus ruang habitat Rombong Kubu sehingga terpaksa rombong ini kehilangan tempat tinggal yang alami. Mekanisme industri sawit di Bulangan menyebabkan krisis ekologi akibat perubahan tanaman homogen. Setiap satu batang pohon sawit membutuhkan minimal 50 liter per hari. Hal ini menimbulkan krisis air bersih bagi kebutuhan air Rombong Kubu maupun tanaman dan ekosistem hutan.

Saran pertama dari kajian ini adalah penguatan peran dari Dinas Sosial, Kanwil Agama RI dan Universitas bidang-bidang ilmu sosialbudaya untuk melakukan pendampingan komunitas Kubu yang tercerabut ruang hidupnya dari hutan-hutan Sumatera Barat, sekaligus usaha untuk melakukan dokumentasi dan penghayatan kepercayaan leluhur (native believes) yang semakin sirna. Saran kedua, tanggungjawab institusi publik setempat seperti pemerintahan dan perusahaan yang 
perlu melakukan redefinisi mengenai hak ruang hidup bagi komunitas asli yang minor. Sebagaimana ketentuan Undang-undang Nomor 32 Tahun 2009 tentang perlindungan dan pengelolaan lingkungan yang mewajibkan pelaku perkebunan memenuhi asas "ramah lingkungan" dalam proses produksi industrial.

\section{Acknowledgement}

Ucapan terima kasih kepada Nurul Firmansyah (Program Peduli The Asia Foundation) yang telah memberikan biaya akomodasi penelitian, Masdar Farid, M.A. dan Fuji Riang Prastowo (Staf Dosen Sosiologi FISIP UGM) dalam pelaksanaan kajian.

\section{DAFTAR PUSTAKA}

Arsa, D. (2019). “Literasi Awal pada Anak Usia Dini Suku Anak Dalam Dharmasraya “. Jurnal Obsesi: Jurnal Pendidikan Anak Usia Dini. 3:127-136.

Bappeda Kabupaten Dharmasraya. (2011). Peta Rencana Tata Ruang Kabupaten Dharmasraya. Badan Pembangunan Daerah Kabupaten Dharmasraya Sumatera Selatan Republik Indonesia.

Bosko, R. (2006). Hak-hak Masyarakat Adat: Dalam Konteks Pengelolaan Sumber Daya Alam. Jakarta: Aliansi Masyarakat Adat Nusantara \& Elsam.

Bryman, A. and Burgess. (1994). Analyzing Qualitative Data. New York: Routledge.

Cobo, J. M. (1986). Study of the Problem of Discrimination Againts Indigeneous Populations. In United Nations Documents. E/CN.4/Sub.2.

Deleuze, G. and F. Guattari. (1987). A Thousand Plateaus: Capitalism and Szhizophrenia. Minneapolis: The University of Minnesota Press.6

Diaw, M. Aseh, T and R. Prabhu. (2009). In Search of Common Ground: Adaptive Collaboration Management in Cameroon. Bogor: CIFOR.

Elvawati, D, Arya. D, Didin. Sumarti, T. (2019). "Dari Karet ke Sawit: Transformasi Struktur Nafkah Rumah Tangga Petani Lokal dan Petani Transmigran di Minangkabau “. Sodality: Jurnal Sosiologi Pedesaan. 5:86-94.

Geertz, C. (1983). Involusi Pertanian: Proses Perubahan Ekologi di Indonesia. Jakarta: Bhratara Aksara.

Glaser, B. and A. Strauss. (1967). The Discovery of Grounded Theory: Strategies for Qualitative Research. Chicago, IL: Aldine Publishing. 
Huda, M. T., \& Khasanah, I. K. (2019). Budaya Sebagai Perekat Hubungan Antara Umat Beragama di Suku Tenger. SANGKéP: Jurnal Kajian Sosial Keagamaan, 2(2), 151-170.

Jayadi, S., Demartoto, A., \& Kartono, D. T. (2018). Local Wisdom as the Representation of Social Integration between Religions in Lombok Indonesia. In Annual Civic Education Conference (ACEC 2018). Atlantis Press.

Jeong, H. (2001). "Politics for Global Environmental Governance ". Global Environmental Policies: Institutions and Procedures. London: Palgrave.

Li, T.M. (2000). "Locating Indigeneous Environmental Knowledge in Indonesia".Indigeneous Environmental Knowledge and Its Transformations: Critical Anthropological Approaches. Roy Ellen, Peter Parkes, Alan Bicker (ed).Amsterdam: Harwood Academic Publisher.

Li, T.M. (2001). "Masyarakat Adat, Difference, and The Limits of Recognition in Indonesia's Forest Zone“. Modern Asian Studies. 3:645-676.

Lombard, D. (2018). Nusa Jawa Silang Budaya 1: Batas-batas Pembaratan. Edisi Kelima. Jakarta: Gramedia.

Marvasti, A. (2004). Qualitative Research in Sociology. London:Sage Publication.

Maykut, P. and R. Morehouse. (1994). Beginning Qualitative Research: A Philosophic Practical Guide. Washington: The Falmer Press.

Muazaroh, S., \& Subaidi, S. (2019). Cultural Capital dan Kharisma Kiai dalam Wacana Partai Politik. SANGKéP: Jurnal Kajian Sosial Keagamaan, 2(2), 185-196.

Neuman, W.L. (2014). Social Research Methods. Essex,UK: Pearson International.

Persoon, G. (1989). “The Kubu and The Outside World (South Sumatra, Indonesia): The Modification of Hunting and Gathering ". Anthropos Journal. 84:507-519.

Prasetijo, A. (2007). “Orang Kubu Mencampok Adat: Etnografi Orang Kubu Dalam Tekanan Dominasi Orang Melayu di Jambi “. Thesis. FISIP Universitas Indonesia.

Prasetijo, A. (2015). Orang Rimba, True Custodian of The Forest: Alternative Strategies and Actions in Social Movement Againts Hegemony. Jakarta: ICSD.

Prastowo, F.R, Faridl. M, Arrozy,A. Anggraini, E. (2019). “Inklusi Sosial dalam Masyarakat Adat: Suku Anak Dalam, Dharmasraya dan 
Ahmad Arrozy, dkk

Suku Sawang, Belitung". Golong Gilig Research Team E Program Peduli The Asia Foundation.

Strauss, A. and J. Corbin. (1994). Handbook of Qualitative Research. Thousand Oaks, CA: Sage Publication.

Syuroh, M. (2011). "Reinterpretasi dari Program Pembinaan ke Pemberdayaan Dalam Pelestarian Ekologi Suku Terasing di Indonesia (Studi Kasus Suku Kubu di Sumatera) “. Bumi Lestari: Journal of Environment. 11:178-189.

Zoa, M. (2009). "Community Forest: Reconciling Customary and Legal Concept". In Search of Common Ground. Mariteuw Diaw, Tony Aseh, Ravi Prabhu (ed). Bogor: CIFOR. 